\title{
Sistema de Custeio baseado em Atividades: Um estudo realizado no âmbito de uma Empresa Prestadora de Serviços Contábeis
}

\author{
Célio Beserra de Sá \\ Mestrando em andamento em Controladoria pela Universidade Federal Rural de \\ Pernambuco - UFRPE \\ Rua Dom Manuel de Medeiros, s/n. Dois Irmãos. Recife/PE. CEP: 52171-900 \\ E-mail: celio.beserra@yahoo.com.br \\ Antônio André Cunha Callado \\ Doutorado em Administração pela Universidade Federal da Paraíba - UFPB \\ Professor da Universidade Federal Rural de Pernambuco - UFRPE \\ Rua Dom Manuel de Medeiros, s/n. Dois Irmãos. Recife/PE. CEP: 52171-900 \\ E-mail: andrecallado@yahoo.com.br
}

\section{RESUMO}

O objetivo deste artigo foi demonstrar a viabilidade do sistema $A B C$ para a análise das atividades e custos fixos com salários em uma empresa de serviços contábeis. Para a consecução desse objetivo foi realizada uma pesquisa exploratória, descritiva, documental e qualitativa, operacionalizada através de um estudo de caso. Todas as informações necessárias foram coletadas através de entrevistas, observação direta e pesquisa documental. Foram identificadas 22 atividades, as quais foram analisadas considerando 5 categorias (recursos humanos, tempo, frequência, complexidade e importância). Para a análise dos resultados foram consideradas duas técnicas: análise do conteúdo e do discurso. Para dar maior consistência à análise dos resultados foi utilizada uma abordagem por triangulação. Através dos resultados, possibilitou-se depreender que, em relação às atividades mais caras, os departamentos contábil e pessoal possuem semelhanças quanto à essência da atividade, pois suas atividades mais caras são atividades mais analíticas e que exigem menos trabalho manual, ao passo que no departamento fiscal a atividade mais cara é essencialmente manual e que requer menos capacidade analítica. Foi possível visualizar a aplicação e viabilidade do $A B C$ para a análise das atividades realizadas nos departamentos contábil, fiscal e pessoal, destacando a identificação das atividades mais onerosas, como também as relações existentes entre as atividades com base em direcionadores definidos. Pode-se concluir que $\mathrm{O} A B C$ é uma ferramenta gerencial apropriada para a análise das atividades e custos fixos com salários em empresas de serviços contábeis.

Palavras-chave: Análise de Custos. Sistema ABC. Custos no Setor de Serviços. 
Sistema de Custeio baseado em Atividades: Um estudo realizado no âmbito de uma Empresa

Prestadora de Serviços Contábeis

Célio Beserra de Sá, Antônio André Cunha Callado

\title{
Activity based Costing System: A study performed in the Framework of a Company Providing Accounting Services
}

\begin{abstract}
The objective of this article is to demonstrate the viability of $A B C$ system for the analysis of activities and fixed costs, such as salaries in an accounting services company. To achieve this objective anexploratory, descriptive, documentary and qualitative research was carried out, and operationalized under a case study method. All necessary information was collected in interviews, direct observation and documentary research. Twenty two activities were identified, which were analyzed considering 5 categories (human resources, time, frequency, complexity and importance). For the analysis of the results, two techniques were considered: content and discourse analysis. To give greater consistency to the analysis of the results, a triangulation approach was used. Through the results, it is possible to conclude that in relation to the most expensive activities, the accounting and personnel departments have similarities as to the essence of the activity, since their most expensive activities are more analytical activities and require less manual labor, whereas in the tax department the more expensive activity is essentially manual and requires less analytical skills. It was possible to visualize the application and feasibility of $A B C$ for the analysis of the activities carried out in the accounting, tax and personnel departments, highlighting the identification of the most costly activities, as well as the existing relationships between the activities based on defined drivers. It can be concluded that $A B C$ is an appropriate management tool for the analysis of activities and fixed costs with salaries in accounting services companies.
\end{abstract}

Keywords: Cost analysis. ABC system. Costs in the service sector.

\section{Sistema de Costos basado en Actividades: Un Estudio realizado en el marco de una Empresa que oferece Servicios de Contabilidad}

\section{RESUMEN}

El objetivo de este artículo fue demostrar la viabilidad del sistema $A B C$ para el análisis de actividades y costos fijos con salarios en una empresa de servicios de contabilidad. Para lograr este objetivo, se llevó a cabo una investigación exploratoria, descriptiva, documental y cualitativa, operativa a través de un estudio de caso. Toda la información necesaria se recopiló a través de entrevistas, observación directa e investigación documental. Se identificaron 22 actividades, que se analizaron considerando 5 categorías (recursos humanos, tiempo, frecuencia, complejidad e importancia). Para el análisis de los resultados, se consideraron dos técnicas: análisis de contenido y discurso. Para dar más consistencia al análisis de los resultados, se utilizó un enfoque de triangulación. A través de los resultados, fue posible concluir que en relación con las 
actividades más caras, los departamentos de contabilidad y personal tienen similitudes con respecto a la esencia de la actividad, ya que sus actividades más caras son actividades más analíticas y requieren menos trabajo manual, mientras que en el departamento de impuestos La actividad más costosa es esencialmente manual y requiere menos habilidades analíticas. Fue posible visualizar la aplicación y la viabilidad de ABC para el análisis de las actividades llevadas a cabo en los departamentos de contabilidad, impuestos y personal, destacando la identificación de las actividades más costosas, así como las relaciones existentes entre las actividades basadas en conductores definidos. Se puede concluir que $A B C$ es una herramienta de gestión adecuada para el análisis de actividades y costos fijos con salarios en empresas de servicios contables.

Palabras clave: Análisis de Costos. Sistema ABC. Costos en el Sector Servicios.

\section{INTRODUÇÃO}

A conjuntura econômica da qual as organizações fazem parte é composta por excessiva competitividade, o que impulsiona as empresas cada vez mais a adotarem tecnologias que sejam capazes de melhorar os processos internos e munir os gestores de informações relevantes a fim da tomada de decisões assertivas (Catelli \& Guerreiro, 1993). A aludida competitividade é consequência da globalização dos mercados, em que as empresas competem na variedade da oferta de produtos e serviços, qualidade e atratividade de preços (Stefano, 2011).

A globalização dos mercados não só implicou no aumento da competitividade entre as organizações, mas também influenciou na forma como as empresas tratam e gerem os seus custos, pois diante do grande volume de informações envolvidas nos processos internos, as ações relacionadas aos custos passaram a ser uma das principais estratégias organizacionais (Pereira Filho \& Amaral, 1998).

Com base nisso, tem-se que as técnicas de custeamento e ações voltadas ao controle de custos são artefatos gerenciais importantes para o processo decisório e desempenho empresarial (Abbas, Gonçalves, \& Leoncine, 2012). Para Canha (2007), as ferramentas gerenciais devem servir para a geração de informações úteis e 
relevantes, o que se torna possível através das tecnologias adotadas e estratégias desenvolvidas.

Dentre as ferramentas gerenciais utilizadas, especificamente ferramentas relacionadas ao controle e gestão estratégica de custos, tem destaque no meio empresarial e acadêmico o custeio baseado em atividades (Activity Based Costing$A B C)$, que dentre outras características, difere dos sistemas de custeio tradicionais por considerar as atividades como as principais consumidoras de recursos e geradoras de custos (Beuren \& Roedel, 2002). De acordo com Canha (2007), "o ABC mostrou-se uma ferramenta da contabilidade de gestão que lhe permite não só apurar os custos, mas também rever os próprios processos de atividades praticados pela empresa, ou seja, permite também dominar os custos".

Em relação a esse aspecto, argumenta-se acerca dos benefícios da utilização do sistema $A B C$ em empresas prestadoras de serviços, pelo fato de que nessas empresas uma parcela significativa dos gastos é constituída por elementos fixos, tais como os custos fixos com salários (Mauad \& Pamplona, 2001; Zanetti, 2003). Destarte, o sistema $A B C$, que originalmente fora desenvolvido nas indústrias manufatureiras, é aplicável e potencialmente útil em empresas prestadoras de serviços (Dalmácio, Rezende, \& de Aguiar, 2007; Stefano, 2011).

Empresas prestadoras de serviços são aquelas que oferecem atos ou desempenhos a outrem, de maneira impessoal, cuja relação não envolve transferência de bens tangíveis, resultando na satisfação das expectativas e necessidades dos clientes, que se sentem compensados pelo gasto empreendido (Corrêa, 2002). Com base na definição apresentada, tem-se que organizações contábeis são empresas caracterizadas como prestadoras de serviços (Anjos, Santos, Miranda, Silva, \& Santana, 2011). Nessa linha de abordagem, Rodrigues e Lemos (2009) vão além ao explicar que organizações contábeis atuam como prestadoras de serviços para outras organizações ou entidades, pois essas últimas buscam descentralizar as atividades meio no intento de concentrar esforços nas atividades fins. 
Embora o Sistema $A B C$ seja mais do que um método de alocação, seu atributo principal que o diferencia das demais metodologias é a maneia pela qual ele acumula e aloca custos (Stratton, Desroches, Lawson, \& Hatch, 2009). O sistema ABC foi concebido no contexto de empresas industriais, mas seus princípios são plenamente aplicáveis a outras modalidades de empresas (Chea, 2011). Com base nisso, e também considerando a natureza exploratória da pesquisa, escolheu-se o setor de serviços por ser pouco estudado em se tratando do ABC.

Então, considerando que o sistema $A B C$ é aplicável e potencialmente útil em organizações que atuam na área da prestação de serviços, a exemplo das organizações contábeis, o presente trabalho tem como objetivo demonstrar a viabilidade do sistema $A B C$ para a análise das atividades e custos fixos com salários em uma empresa de serviços contábeis.

Poucos estudos correlatos à proposta colocada em tela foram identificados, a exemplo do estudo de Liba, Robles e Bacci (2001), cujo objetivo foi demonstrar os custos incorridos em uma organização contábil sob a perspectiva do $A B C$, e o estudo de Kühl, Cogan, Júnior, \& Canan (2006), que simula a aplicação do ABC em uma organização contábil. Dessa forma, a realização do presente trabalho se justifica, em um primeiro momento, em razão da escassez na literatura nacional e internacional de estudos empíricos acerca do $A B C$ em organizações contábeis, sendo necessário expandir os estudos em empresas desse tipo.

Em termos práticos, a pesquisa se justifica pela identificação de uma necessidade informacional no que cerne à empresa objeto deste estudo em ter uma melhor gestão das suas atividades, haja vista que não fora identificada nenhuma prática gerencial nesse sentido. Outrossim, o sistema $A B C$ poderá ajudar a empresa a conhecer melhor as suas atividades e proceder à gestão adequada dos seus custos, sobretudo aqueles que mais impactam os seus resultados, como é o caso dos custos fixos com salários.

O artigo está estruturado em cinco seções, sendo iniciado pela presente introdução, seguida do referencial teórico sobre o $A B C$, metodologia, apresentação e 
Sistema de Custeio baseado em Atividades: Um estudo realizado no âmbito de uma Empresa

Prestadora de Serviços Contábeis

Célio Beserra de Sá, Antônio André Cunha Callado

análise dos dados e, por fim, as considerações finais com base nos achados do estudo são apresentadas.

\section{SISTEMA DE CUSTEIO BASEADO EM ATIVIDADES}

A literatura diverge em relação ao surgimento do método, sobretudo no que cerne ao marco inicial do desenvolvimento e utilização de tal sistema de custeio. Mas, basicamente, há duas correntes de pensamento: uma aponta que o $\mathrm{ABC}$ pode ser entendido como uma inovação no que diz respeito aos processos de custeio; e outra que argumenta na linha de pensamento de que o $A B C$ é semelhante a outros métodos existentes, não representando propriamente uma inovação (Stefano, 2011).

Há registros na literatura de que o $A B C$ já fora utilizado por volta dos anos 1800 e início dos anos 1900, primariamente como um método alemão de custeio, até evoluir para o método $A B C$ que se conhece hoje em dia (Nakagawa, 1995).

Entretanto, também é apresentado que o $A B C$ foi desenvolvido e codificado nos Estados Unidos na década de 80, por Kaplan e Cooper, em resposta aos anseios empresariais da época, que permeavam em torno da necessidade de se ter uma ferramenta que fosse capaz de ajudar as organizações a controlarem melhor os seus custos e se manterem de forma mais eficiente ante ao mercado (Allain \& Laurin, 2018; Jericó, 2008; Mauad \& Pamplona, 2001).

No Brasil, os estudos sobre o $A B C$ tiveram início a partir de 1989, na Universidade de São Paulo (USP), especificamente no departamento de Contabilidade e Atuária da Faculdade de Economia, Administração e Contabilidade da referida academia (Nakagawa, 1995).

O sistema $A B C$ representa uma metodologia através da qual é possível se obter informações mais acuradas dos custos, processos, atividades e tarefas realizadas em uma organização, razão pela qual se torna relevante para o fornecimento de subsídios para a tomada de decisões estratégicas. É importante ressaltar que o $A B C$ deve ser utilizado de maneira suplementar ao sistema de custeio tradicional utilizado pela 
organização, pois o mesmo é voltado para o fornecimento de dados para decisões gerenciais, ao passo que um sistema de custeio tradicional é voltado para o fornecimento de dados para a produção de relatórios financeiros externos (Compton, 1996; Garrison, Noreen, \& Brewer, 2013).

De acordo com Canha (2007, p. 52), a principal filosofia do método ABC "é a de que os produtos consomem atividades e as atividades consomem recursos, contrariando o custeio tradicional que diz que os produtos consomem os recursos (ou os custos)".

No custeio tradicional os custos são acumulados por departamentos, para então serem atribuídos aos produtos e serviços através de critérios volumétricos de rateio, diferentemente, no método $A B C$, que o foco está voltado para os recursos e como as atividades consomem tais recursos (Cogan, 2006; Jericó \& Castilho, 2010).

$\mathrm{O} A B C$ atribui os custos indiretos e despesas, inicialmente, às atividades, para posteriormente atribuir aos objetos de custeio, que podem ser produtos ou serviços. A atribuição ocorre por meio dos chamados direcionadores de custos (cost driver), que funcionam como uma forma de associação entre os recursos e as atividades e ainda entre as atividades e os objetos de custeio (Dalmácio et al., 2007).

Conforme Stefano (2011), "os direcionadores de custos são a base do ABC, e procuram rastrear a origem do custo e estabelecer uma relação de causa/efeito". Então, entende-se que os direcionadores de custos é uma forma de associar e atribuir custos às atividades executadas.

Uma das peculiaridades do $A B C$ é que o mesmo contempla todos os gastos diretos e indiretos envolvidos no processo de produção ou prestação do serviço, pois se leva em consideração a relação de causa e efeito, ou seja, no método $A B C$ não importa se o gasto é direto ou indireto, mas sim, se houve participação efetiva de tal gasto em relação a um determinado produto ou serviço, e, se não houve participação, o gasto não é levado em consideração no custeamento (Cogan, 1999; Garrison et al., 2013; Miranda et al., 2007; Wernke, 2005). 
Consoante Khoury e Ancelevicz (2000) "o ABC tem como principais objetivos: a) obter informação mais acurada dos custos dos produtos produzidos e/ou serviços prestados; b) identificar os custos relativos das atividades e as razões de essas atividades serem empreendidas".

Destarte, pode-se entender que o uso do sistema $A B C$ é pertinente para empresas que desejam conhecer melhor os seus custos e entender de forma mais efetiva os processos desenvolvidos internamente, possibilitando realizar melhorias e até mesmo excluir atividades que não agregam valor ao produto ou serviço (Canha, 2007; Santos, 1998; Stefano, 2011).

Para que seja implantado um sistema $A B C$ é necessário seguir algumas etapas, que se relacionam e se complementam para que o sistema possa atingir os objetivos propostos. Uma implantação bem-sucedida do método $A B C$ está intrinsecamente relacionada ao apoio da alta administração, de modo que os líderes devem sensibilizar os seus colaboradores acerca da importância e benefícios que o $A B C$ irá proporcionar à organização, quando implantado e mantido da maneira adequada, para isso, sendo indispensável o engajamento de toda a equipe (Canha, 2007).

$\mathrm{Na}$ concepção de Stefano (2011), "primeiramente, é necessário avaliar como as atividades consomem os recursos (cost drivers dos recursos e da primeira fase), tentando estabelecer uma relação entre ambos e, em seguida, como os produtos e ou serviços consomem as atividades". A autora adverte que a identificação das atividades e direcionadores de custos devem ser feitos de maneira bastante cuidadosa, pois na lógica do $A B C$ esses elementos serão os que vão de fato fornecer subsídios para a atribuição de custos aos objetos de custeio.

Segundo Kaplan e Anderson (2004), o procedimento padrão para proceder à implantação do $A B C$ tem início com a identificação e mapeamento das atividades relevantes que são executadas na organização, inclusive deve-se também proceder à identificação dos recursos que serão utilizados na realização de cada atividade que faz parte da operação da empresa. 
Como toda ferramenta, o ABC possui vantagens e desvantagens, que devem ser lavadas em consideração antes do processo de implantação na empresa, pois deve-se comparar os prós e os contras para então decidir se a ferramenta é interessante ou não para a organização. De acordo com Pereira (2015), dentre as principais vantagens do custeio ABC, destacam-se as seguintes: "calcular de forma mais acurada os custos dos objetos de custeio; ampliar o objeto de análise: não se restringe ao custo dos produtos e lucratividade; revelar informações acerca de todo o processo de produção; fornecer informações do custo das atividades".

$\mathrm{Na}$ opinião de Khodadadzadeh (2015), a principal vantagem do $A B C$ reside no fato de que através do mesmo torna-se possível identificar quais produtos ou serviços não são rentáveis para a empresa, podendo assim, eliminá-los. A autora ainda ressalta que o $A B C$ pode ajudar no ajuste do preço de produtos ou serviços cujos preços são praticados de maneira inadequada. Ademais, o sistema contribui para a redução das distorções na alocação de custos indiretos (Rosa, 2006).

Não obstante, a literatura também apresenta pontos negativos relacionados ao sistema ABC, como pode ser observado no que aduz Pereira Filho e Amaral (1998): "geração de informações confiáveis somente a longo prazo; controle dificultado em empresas com grande número de atividades; o $\mathrm{ABC}$ em sua forma mais detalhada pode não ser aplicável na prática [...]".

Ademais, pode-se apontar o fato de que esse sistema envolve altos custos para a sua implementação, revisão constante, controles complexos a serem desenvolvidos na prática, além de necessitar do engajamento de todos os funcionários e tecnologia da informação desenvolvida (Dalmácio et al., 2007; Kaplan \& Anderson, 2007; Keel Savage, Rafiq, \& Mazzocato, 2017).

Khoury e Ancelevicz (2000) advertem que erros de alocação podem ocorrer quando se leva em consideração entrevistas com funcionários para a definição do tempo de realização das atividades, pois as informações coletadas podem estar dotadas de imprecisão e subjetividade. 


\section{METODOLOGIA}

A pesquisa é classificada como exploratória e descritiva em relação ao objetivo, sendo qualitativa no que diz respeito à abordagem do problema, cuja operacionalização se dá através de um estudo de caso e se utiliza das técnicas de entrevista, observação e pesquisa documental para a coleta dos dados e informações. No que diz respeito às técnicas de análise, empregou-se a análise de conteúdo e do discurso. A fim de agregar maior consistência às análises empreendidas, de forma suplementar, utilizouse a técnica da triangulação, sendo trianguladas as entrevistas obtidas, observações realizadas e documentos visualizados.

O caso em estudo consiste nos departamentos contábil, fiscal e pessoal de uma empresa prestadora de serviços contábeis de pequeno porte, fundada em 2002, situada na cidade de Caruaru, no interior de Pernambuco, composta por 41 funcionários, distribuídos entre os departamentos considerados e outras áreas, tais como recepção, secretaria, limpeza e vigilância. Há também a figura do diretor, que é o contador responsável e proprietário da empresa. O critério de escolha do caso estudado foi a acessibilidade e o tipo de empresa, pois a literatura aborda que o $A B C$ se adequa bem a empresas prestadoras de serviços, conforme defendido por Kaplan e Cooper (1998), ao argumentarem que em organizações desse tipo aparentemente todos os custos são fixos, tais como os salários dos funcionários.

A Figura 1 apresenta a estrutura dos departamentos considerados na análise, como também o número de funcionários envolvidos nas atividades que são realizadas em cada departamento. 
Sistema de Custeio baseado em Atividades: Um estudo realizado no âmbito de uma Empresa

Prestadora de Serviços Contábeis Célio Beserra de Sá, Antônio André Cunha Callado

\begin{tabular}{|c|c|}
\hline \multicolumn{2}{|c|}{ DEPARTAMENTO CONTÁBIL } \\
\hline Função & Quantidade de funcionários \\
\hline Gerente do departamento & 1 \\
\hline Coordenador de empresas & 6 \\
\hline Auxiliar contábil & 3 \\
\hline Estagiário & 1 \\
\hline \multicolumn{2}{|c|}{ DEPARTAMENTO FISCAL } \\
\hline Função & Quantidade de funcionários \\
\hline Gerente do departamento & 1 \\
\hline Coordenador de empresas & 9 \\
\hline Auxiliar fiscal & 5 \\
\hline Estagiário & 1 \\
\hline \multicolumn{2}{|c|}{ DEPARTAMENTO PESSOAL } \\
\hline Função & Quantidade de funcionários \\
\hline Gerente do departamento & 1 \\
\hline Analista de departamento pessoal & 2 \\
\hline Auxiliar de departamento pessoal & 2 \\
\hline
\end{tabular}

Figura 1. Estrutura dos departamentos

Fonte: Elaboração própria (2019).

Nas rotinas do departamento contábil são executadas 8 atividades relevantes, no departamento fiscal foram identificadas 7 atividades relevantes e, por fim, no departamento pessoal 7 atividades foram elencadas, totalizando 22 atividades identificadas, que foram devidamente explanadas na parte dos resultados. Para analisar as atividades executadas foram consideradas as seguintes categorias extraídas do estudo de Arruda e Callado (2018): recursos humanos (custo fixo com salário); tempo (direcionador de custo); frequência (direcionador de custo); complexidade (direcionador de custo); e, importância (direcionador de custo).

A categoria recursos humanos (custo fixo com salário) foi operacionalizada através da associação entre as atividades realizadas e o tempo consumido na execução das mesmas. Nesta pesquisa foram considerados apenas os custos fixos com salário bruto, não levando em consideração encargos sociais e benefícios pagos ao trabalhador, como por exemplo, INSS patronal, FGTS, vale alimentação e vale 
Sistema de Custeio baseado em Atividades: Um estudo realizado no âmbito de uma Empresa

Prestadora de Serviços Contábeis

Célio Beserra de Sá, Antônio André Cunha Callado

transporte. Contudo, salienta-se que a abordagem do ABC pode ser estendida também a esses e demais custos, porém, mais informações nesse sentido não foram fornecidas pela empresa estudada.

Nas entrevistas efetuadas, primeiramente, questionou-se junto aos gerentes dos departamentos quais as atividades relevantes são realizadas mensalmente nas rotinas de cada um dos departamentos, em seguida, questionou-se junto a todos os trabalhadores a respeito de quais atividades identificadas pelos líderes dos departamentos que cada funcionário executa e o tempo (em dias por mês, posteriormente transformados em horas) que se leva para executar cada atividade. Destaca-se que todos os funcionários executam mais de uma das atividades relacionadas, por isso a necessidade de fazer a alocação do salário dentre elas. A seguir é demonstrada a trajetória percorrida para se chegar ao custo fixo total com salários por mês de cada atividade analisada:

- somou-se a quantidade de dias no mês que são necessários para realizar todas as atividades em relação a cada funcionário;

- dividiu-se os dias de cada atividade pela soma de todos os dias, e em seguida multiplicou-se por 100, para saber a porcentagem em relação ao tempo que cada atividade consome do salário do mês;

- calculou-se as porcentagens encontradas de cada atividade sobre o salário do mês, alocando-se o salário dentre as atividades realizadas. Fez-se isso com todos os funcionários dos três departamentos;

- por fim, somou-se as parcelas alocadas dos salários de todos os funcionários do departamento por atividade, chegando-se ao total do custo fixo com salário no mês de cada atividade identificada pelos líderes entrevistados.

As informações relativas aos salários foram coletadas a partir do relatório da folha de pagamento de junho de 2019. As entrevistas, que foram transcritas, e observações, foram realizadas durante 4 dias completos de expediente, totalizando 32 horas e ocorreram durante a primeira quinzena de julho de 2019. 
Sistema de Custeio baseado em Atividades: Um estudo realizado no âmbito de uma Empresa

Prestadora de Serviços Contábeis Célio Beserra de Sá, Antônio André Cunha Callado

A Figura 2 apresenta as escalas ordinais de três níveis em que as outras categorias da pesquisa foram analisadas.

\begin{tabular}{|l|c|c|c|}
\hline \multicolumn{1}{|c|}{ Categoria de análise } & Nível 1 & Nível 2 & Nível 3 \\
\hline Frequência & Rara & Regular & Frequente \\
\hline Complexidade & Baixa & Média & Alta \\
\hline Importância & Pouco importante & Importante & Muito importante \\
\hline
\end{tabular}

Figura 2. Categorias analisadas

Fonte: Elaboração própria (2019).

Com base na Figura 2, ao se identificar as atividades, questionou-se aos gerentes dos departamentos em qual nível estava cada atividade considerando as categorias analisadas. Concomitantemente às entrevistas, observações também foram feitas durante a realização das atividades, sobretudo no que diz respeito às categorias analisadas, com vistas a corroborar o que estava sendo dito nas entrevistas.

\section{APRESENTAÇÃO E ANÁLISE DOS DADOS}

Com base nos dados e informações coletadas, foram analisadas as atividades relevantes executadas nos três departamentos considerados no presente estudo. $O$ primeiro departamento cujas atividades foram analisadas sob a ótica do sistema $A B C$ foi o departamento contábil. Sobre esse departamento é relevante destacar que:

"A principal atribuição do departamento contábil é fornecer informações através de relatórios contábeis que possam auxiliar na tomada de decisão dos administradores. Sua importância é dar direcionamento aos clientes por meio das informações geradas." (Gerente do departamento).

$\mathrm{Na}$ Figura 3 são apresentadas as atividades realizadas no departamento contábil, como também as categorias de informações consideradas na análise, os 
Sistema de Custeio baseado em Atividades: Um estudo realizado no âmbito de uma Empresa

Prestadora de Serviços Contábeis

Célio Beserra de Sá, Antônio André Cunha Callado

direcionadores de custo, assim como os custos das atividades considerando os recursos humanos, ou seja, os custos fixos com salário.

\begin{tabular}{|l|c|c|c|c|c|c|}
\hline \multicolumn{1}{|c|}{ Atividade } & $\begin{array}{c}\text { Tempo de } \\
\text { pessoas }\end{array}$ & $\begin{array}{c}\text { Noara } \\
\text { realização } \\
\text { (h) }\end{array}$ & Frequência & Complexidade & Importância & $\begin{array}{c}\text { Custo da } \\
\text { atividade } \\
\text { (salário) }\end{array}$ \\
\hline $\begin{array}{l}\text { Contabilização } \\
\text { da folha de } \\
\text { pagamento }\end{array}$ & 7 & 160 & Regular & Média & $\begin{array}{c}\text { Muito } \\
\text { importante }\end{array}$ & 934,18 \\
\hline $\begin{array}{l}\text { Contabilização } \\
\text { das despesas }\end{array}$ & 9 & 336 & Frequente & Média & $\begin{array}{c}\text { Muito } \\
\text { importante }\end{array}$ & $1.628,44$ \\
\hline $\begin{array}{l}\text { Importação do } \\
\text { movimento } \\
\text { fiscal de }\end{array}$ & 8 & 160 & Frequente & Alta & $\begin{array}{c}\text { Muito } \\
\text { importante }\end{array}$ & 988,64 \\
\hline $\begin{array}{l}\text { Baixa } \\
\text { duplicatas }\end{array}$ & 8 & 272 & Frequente & Média & $\begin{array}{c}\text { Muito } \\
\text { importante }\end{array}$ & $1.413,05$ \\
\hline $\begin{array}{l}\text { Contabilização } \\
\text { do extrato } \\
\text { bancário }\end{array}$ & 9 & 296 & Frequente & Média & $\begin{array}{c}\text { Muito } \\
\text { importante }\end{array}$ & $1.838,21$ \\
\hline $\begin{array}{l}\text { Importação da } \\
\text { depreciação do } \\
\text { módulo } \\
\text { patrimonial }\end{array}$ & 6 & 56 & Regular & Média & $\begin{array}{c}\text { Muito } \\
\text { importante }\end{array}$ & 345,97 \\
\hline $\begin{array}{l}\text { Conciliação das } \\
\text { contas do } \\
\text { balancete }\end{array}$ & 9 & 920 & Regular & Alta & $\begin{array}{l}\text { Muito } \\
\text { importante }\end{array}$ & $5.520,01$ \\
\hline $\begin{array}{l}\text { Análise das } \\
\text { demonstrações } \\
\text { contábeis }\end{array}$ & 2 & 168 & Regular & Alta & $\begin{array}{l}\text { Muito } \\
\text { importante }\end{array}$ & $2.081,78$ \\
\hline
\end{tabular}

Figura 3. Atividades do departamento contábil

Fonte: Elaboração própria (2019).

O segundo departamento que teve suas atividades e custos fixos com salários analisados sob a perspectiva do sistema $A B C$ foi o departamento fiscal. Esse é maior departamento da empresa estudada, em termos de quantidade de funcionários. Sobre esse departamento é pertinente aduzir que: 
Sistema de Custeio baseado em Atividades: Um estudo realizado no âmbito de uma Empresa

Prestadora de Serviços Contábeis

Célio Beserra de Sá, Antônio André Cunha Callado

"O departamento fiscal atende obrigações exigidas pelo fisco Estadual e Federal, gerando o envio de declarações fiscais e impostos. Seu principal papel é identificar a classificação fiscal de produtos e serviços das empresas." (Gerente do departamento).

Na Figura 4 está disposto o detalhamento das atividades do departamento fiscal e as categorias analisadas, como também os custos das atividades com base nos salários dos funcionários lotados nesse departamento.

\begin{tabular}{|l|c|c|c|c|c|c|}
\hline \multicolumn{1}{|c|}{ Atividade } & $\begin{array}{c}\text { Tempo } \\
\text { para } \\
\text { pessoas }\end{array}$ & $\begin{array}{c}\text { Nealização } \\
\text { (h) }\end{array}$ & Frequência & Complexidade & Importância & $\begin{array}{c}\text { Custo da } \\
\text { atividade } \\
\text { (salário) }\end{array}$ \\
\hline $\begin{array}{l}\text { Baixar notas } \\
\text { fiscais }\end{array}$ & 15 & 184 & Regular & Baixa & $\begin{array}{c}\text { Muito } \\
\text { importante }\end{array}$ & $1.924,53$ \\
\hline $\begin{array}{l}\text { Geração de } \\
\text { planilhas com o } \\
\text { movimento para } \\
\text { envio ao cliente }\end{array}$ & 6 & 72 & Regular & Baixa & $\begin{array}{c}\text { Muito } \\
\text { importante }\end{array}$ & 805,09 \\
\hline $\begin{array}{l}\text { Escrituração de } \\
\text { notas fiscais }\end{array}$ & 15 & 560 & Frequente & Alta & $\begin{array}{c}\text { Muito } \\
\text { importante }\end{array}$ & $6.461,23$ \\
\hline $\begin{array}{l}\text { Conferência de } \\
\text { notas fiscais }\end{array}$ & 15 & 568 & Frequente & Alta & $\begin{array}{c}\text { Muito } \\
\text { importante }\end{array}$ & $5.973,34$ \\
\hline $\begin{array}{l}\text { Transmissão de } \\
\text { obrigações } \\
\text { acessórias do }\end{array}$ & 10 & 320 & Frequente & Alta & $\begin{array}{c}\text { Muito } \\
\text { importante }\end{array}$ & $4.076,28$ \\
\hline $\begin{array}{l}\text { Cálculo } \\
\text { diferencial de } \\
\text { alíquotas para } \\
\text { aquisições } \\
\text { interestaduais }\end{array}$ & 11 & 200 & Regular & Alta & $\begin{array}{c}\text { Muito } \\
\text { importante }\end{array}$ & $2.521,13$ \\
\hline $\begin{array}{l}\text { Pesquisas } \\
\text { relacionadas à } \\
\text { tributação } \\
\text { regulação das } \\
\text { rotinas fiscais }\end{array}$ & 1 & 160 & Regular & Alta & Muito & $1.723,25$ \\
\hline
\end{tabular}

Figura 4. Atividades do departamento fiscal

Fonte: Elaboração própria (2019). 
Sistema de Custeio baseado em Atividades: Um estudo realizado no âmbito de uma Empresa

Prestadora de Serviços Contábeis Célio Beserra de Sá, Antônio André Cunha Callado

Por fim, o terceiro e último departamento que teve suas atividades e custos com salários analisados sob a ótica do sistema $A B C$ foi o departamento pessoal. Em relação a esse departamento é importante apresentar que:

"A principal atribuição do departamento pessoal é administrar e controlar as rotinas trabalhistas. Sua importância consiste em assegurar a conformidade às regulações trabalhistas." (Gerente do departamento).

A Figura 5 dispõe as atividades que são executadas no departamento pessoal, em conjunto com as informações das categorias analisadas e custos apurados no que cerne aos salários.

\begin{tabular}{|l|c|c|l|l|l|c|}
\hline \multicolumn{1}{|c|}{ Atividade } & $\begin{array}{c}\text { No de } \\
\text { pessoas }\end{array}$ & $\begin{array}{c}\text { Tempo } \\
\text { para } \\
\text { realização } \\
\text { (h) }\end{array}$ & Frequência & Complexidade & Importância & $\begin{array}{c}\text { Custo da } \\
\text { atividade } \\
\text { (salário) }\end{array}$ \\
\hline $\begin{array}{l}\text { Lançamento das } \\
\text { informações } \\
\text { trabalhistas } \\
\text { enviadas pelos } \\
\text { clientes }\end{array}$ & 5 & 120 & Frequente & Alta & $\begin{array}{c}\text { Muito } \\
\text { importante }\end{array}$ & 915,73 \\
\hline $\begin{array}{l}\text { Conferência das } \\
\text { informações } \\
\text { lançadas }\end{array}$ & 5 & 80 & Frequente & Alta & $\begin{array}{c}\text { Muito } \\
\text { importante }\end{array}$ & 656,65 \\
\hline $\begin{array}{l}\text { Geração dos } \\
\text { tributos } \\
\text { trabalhistas }\end{array}$ & 5 & 80 & Frequente & Alta & $\begin{array}{c}\text { Muito } \\
\text { importante }\end{array}$ & 681,55 \\
\hline $\begin{array}{l}\text { Transmissão de } \\
\text { obrigações } \\
\text { acessórias }\end{array}$ & 5 & 232 & Regular & Alta & $\begin{array}{c}\text { Muito } \\
\text { importante }\end{array}$ & $2.320,86$ \\
\hline $\begin{array}{l}\text { Procedimento de } \\
\text { admissão e } \\
\text { demissão de } \\
\text { funcionários }\end{array}$ & 5 & 272 & Frequente & Média & $\begin{array}{c}\text { Muito } \\
\text { importante }\end{array}$ & $1.950,67$ \\
\hline $\begin{array}{l}\text { Controle de férias } \\
\text { dos funcionários }\end{array}$ & 5 & 40 & Frequente & Média & $\begin{array}{c}\text { Muito } \\
\text { importante }\end{array}$ & 384,07 \\
\hline $\begin{array}{l}\text { Cálculo de férias } \\
\text { vincendas }\end{array}$ & 5 & 48 & Frequente & Média & $\begin{array}{c}\text { Muito } \\
\text { importante }\end{array}$ & 449,56 \\
\hline
\end{tabular}

Figura 5. Atividades do departamento pessoal

Fonte: Elaboração própria (2019). 
Com base nos dados e informações supra apresentados, pode-se observar que todas as atividades identificadas junto aos gerentes dos departamentos são consideradas muito importantes. Nesse sentido, questionada sobre o porquê de todas as atividades do departamento fiscal serem classificadas no nível máximo na categoria importância, a gerente do departamento explicou que o não cumprimento de quaisquer atividades apresentadas na Figura 4 implica no pagamento de multas e juros por parte dos clientes e dos funcionários que as executam. Esse mesmo pensamento foi externado pela gerente do departamento pessoal.

Em se tratando do departamento contábil, essa preocupação não foi enfatizada pelo gerente do departamento, e dentre outros fatores observados, isso se deve ao fato de que esse departamento possui menos prazos de órgãos reguladores a serem cumpridos.

Em relação às atividades mais caras, em se tratando de recursos humanos (custos fixos com salário), os resultados permitem identificar semelhanças e diferenças entre os departamentos. No caso do departamento contábil a atividade mais cara foi a atividade de conciliação das contas do balancete, cujo custo figura na ordem de $R \$$ $5.520,01$, para o departamento fiscal, a atividade mais cara é a de escrituração de notas fiscais, custando $R \$ 6.461,23$, já no departamento pessoal a atividade mais cara é a de transmissão de obrigação acessória, cujo o custo é de $R \$ 2.320,86$.

Dessa forma, pode-se depreender que em relação às atividades mais caras os departamentos contábil e pessoal possuem semelhanças quanto à essência da atividade, pois suas atividades mais caras são atividades mais analíticas e que exigem menos trabalho manual, ao passo que no departamento fiscal a atividade mais cara é essencialmente manual e requer menos capacidade analítica em comparação aos departamentos contábil e pessoal.

Sobre o tempo, os resultados permitem observar que, no departamento fiscal e pessoal, as atividades de conferência de notas fiscais e procedimento de admissão e demissão, respectivamente, são as atividades que consomem mais tempo dos 
funcionários, mas ao mesmo tempo que consomem mais tempo, não são as atividades mais caras.

Por outro lado, no departamento contábil a atividade que consome mais tempo, conciliação das contas do balancete, também é a atividade mais cara. Ainda sobre o tempo, uma peculiaridade pode ser observada no departamento contábil, pois a atividade que consome mais tempo foi classificada como regular na categoria frequência, o que não ocorre nos outros dois departamentos.

Sobre as atividades mais baratas, os três departamentos convergem considerando o fator tempo, pois as atividades que consomem menos tempo obtiveram os menores custos, na ordem de $R \$ 345,97$ no contábil, $R \$ 805,09$ no fiscal e $R \$$ 384,07 no pessoal. Ainda sobre as atividades mais baratas, nota-se que nenhuma delas foi classificada como de complexidade alta, o que é um resultado coerente, pois atividades mais complexas tendem a ser mais caras, inclusive considerando recursos humanos, como pode ser observado nas figuras apresentadas, em que as atividades mais caras dos departamentos foram classificadas no nível máximo da categoria complexidade.

Através dos resultados apresentados foi possível compreender que 0 direcionador de custo tempo é importante e útil para a alocação de custos às atividades, pois permitiu que os custos fixos com salários da empresa estudada pudessem ser quantificados em relação às atividades. Dessa forma, os procedimentos adotados neste trabalho e resultados encontrados corroboram o que defende Kaplan e Anderson (2004), ao afirmarem que o tempo é o único direcionador de custo das atividades, o que simplifica a abordagem do sistema $A B C$. Adicionalmente, é pertinente destacar que Liba et al. (2001) também consideraram o tempo como o principal direcionador para alocar os custos às atividades, assemelhando-se ao que foi desenvolvido na presente pesquisa.

Ademais, os achados deste trabalho vão ao encontro do que apresentaram Kühl et al. (2006), pois com base nos resultados da sua simulação, defenderam a viabilidade da aplicação do $A B C$ em organizações contábeis, argumentando a racionalização dos 
custos. Os autores deram enfoque a dados simulados, diferentemente, este trabalho considerou dados empíricos, fornecendo indícios que puderam sustentar a aplicação prática do que fora simulado pelos autores.

Nesse sentido, além da contribuição teórica, o trabalho também forneceu contribuições práticas, sobretudo para a empresa objeto do estudo, pois os resultados obtidos podem auxiliar a empresa no custeamento dos seus clientes, até mesmo avaliar a lucratividade por cliente. Não obstante, a empresa também pode utilizar as informações obtidas para planejar os gastos com pessoal e decidir acerca da fixação de salários.

\section{CONCLUSÃO}

Este artigo teve como objetivo demonstrar a viabilidade do sistema $A B C$ para a análise das atividades e custos fixos com salários em uma empresa de serviços contábeis. Destarte, possibilitou identificar que todas as atividades foram classificadas no nível máximo da categoria importância, ou seja, são muito importantes.

Estabelecendo-se relação entre as atividades mais onerosas em relação aos custos com salários, identificou-se que as atividades mais caras dos departamentos contábil e pessoal são mais analíticas e exigem menos trabalho manual, diferentemente, no departamento fiscal a atividade mais cara é essencialmente manual e menos analítica.

Sobre o tempo, os achados permitiram observar que, no departamento fiscal e pessoal as atividades que consomem mais tempo não são as mais caras, diferentemente, no departamento contábil a atividade que consome mais tempo também é a mais cara.

Já sobre as atividades mais baratas, os três departamentos apresentam convergência, pois as atividades que consomem menos tempo obtiveram os menores custos. Nenhuma das atividades mais baratas foi classificada no nível máximo da categoria complexidade. 
Sistema de Custeio baseado em Atividades: Um estudo realizado no âmbito de uma Empresa

Prestadora de Serviços Contábeis

Célio Beserra de Sá, Antônio André Cunha Callado

Logo, pode-se concluir que o $A B C$ é uma ferramenta gerencial viável para ser adotada em empresas prestadoras de serviços contábeis, pois possibilita uma análise e entendimento mais amplo acerca das atividades realizadas, como também em relação aos custos fixos com salários.

Como limitação desta pesquisa, pode-se apontar o fato de que, muitas das informações levantadas que serviram de base para as análises empreendidas foram obtidas através de entrevistas com funcionários, o que pode implicar em possíveis imprecisões e distorções nas respostas, o que representa também uma limitação do próprio $\mathrm{ABC}$, conforme explanado no referencial teórico.

Sugere-se para pesquisas futuras proceder à análise das atividades considerando os custos indiretos em empresas contábeis sob a ótica do sistema ABC, de modo que se possa demonstrar a utilidade do método na diminuição das arbitrariedades na alocação de tais custos.

\section{REFERÊNCIAS}

Abbas, K., Gonçalves, M. N., \& Leoncine, M. (2012). Os métodos de custeio: vantagens, desvantagens e sua aplicabilidade nos diversos tipos de organizações apresentadas pela literatura. Contexto, 12(22), 145-159.

Allain, E., \& Laurin, C. (2018). Explaining implementation difficulties associated with activity-based costing through system uses. Journal of Applied Accounting Research, 12(1), 181-198.

Anjos, L. C. M., Santos, P. D. C. F., Miranda, L. C., Silva, D. J. C., \& Santana, F. R. (2011). Conhecer e empreender: um estudo sobre a utilização de artefatos gerenciais em organizações contábeis. Navus-Revista de Gestão e Tecnologia, 1(1), 17-33.

Arruda, L. S., \& Callado, A. A. C. (2018). Custeio baseado em atividade: análise das atividades realizadas no setor de nutrição de um hospital público universitário. RICRevista de Informação Contábil, 12(3), 18-30. 
Beuren, I. M., \& Roedel, A. (2002). O uso do custeio baseado em atividades: ABC (Activity Based Costing) nas maiores empresas de Santa Catarina. Revista Contabilidade \& Finanças, 13(30), 7-18.

Canha, H. M. (2007). O método ABC como factor de competitividade da empresa. Revista TOC, 84, 52-58.

Catelli, A., \& Guerreiro, R. (1993). Mensuração de atividades: comparando ABC" x'GECON". Caderno de Estudos, (8), 01-09.

Chea, A.C. (2011). Activity-Based Costing System in the Service Sector: A Strategic Approach for Enhancing Managerial Decision Making and Competitiveness. International Journal of Business and Management, 6(11), 03-10.

Cogan, S. (1999). Um modelo de reconciliação de dados para o custeio baseado-ematividades (ABC). Revista de Administração de Empresas, 39(2), 46-53.

Cogan, S. (2006). Modelo de custeio baseado em atividades aplicado a decisões de produção de curto prazo. Contabilidade Vista \& Revista, 17(1), 11-27.

Compton, T. R. (1996). Implementing activity-based costing. The CPA Journal, 66(3), 20.

Corrêa, R. C. (2002). Custos em empresas prestadoras de serviços de informática: aplicação do ABC. Dissertação de mestrado. Universidade Federal de Santa Catarina - UFSC, Florianópolis, SC, Brasil.

Dalmácio, F. Z., Rezende, A. J., \& de Aguiar, A. B. (2007). Uma Aplicação do TimeDriven ABC Model no Setor de Serviço Hospitalar: a nova abordagem do ABC proposta por Kaplan e Anderson. Contabilidade Vista \& Revista, 18(2), 11-34.

Garrison, R. H., Noreen, E. W., \& Brewer, P. C. (2013). Contabilidade gerencial. AMGH Editora.

Jericó, M. D. C. (2008). Aplicação do custeio baseado em atividades em um centro de material esterilizado. (Tese de Doutorado). Universidade de São Paulo, USP, São Paulo, Brasil.

Jericó, M. D. C., \& Castilho, V. (2010). Gerenciamento de custos: aplicação de Método de custeio baseado em atividades em centro de material esterilizado. Revista da Escola de Enfermagem da USP, 44(3), 745-752. 
Sistema de Custeio baseado em Atividades: Um estudo realizado no âmbito de uma Empresa

Prestadora de Serviços Contábeis

Célio Beserra de Sá, Antônio André Cunha Callado

Kaplan, R. S., \& Anderson, S. R. (2004). Time-driven activity-based costing. Havard Business Review, 82.

Kaplan, R. S., \& Anderson, S. R. (2007). Custeio baseado em atividades e tempo. Rio de Janeiro, Campus.

Kaplan, R. S., \& Cooper, R. (1998). Custo e desempenho: administre seus custos para ser mais competitivo. São Paulo, Futura.

Keel, G., Savage, C., Rafiq, M., \& Mazzocato, P. (2017). Time-driven activity-based costing in health care: a systematic review of the literature. Health Policy, 121(7), 755-763.

Khodadadzadeh, T. (2015). A state-of-art review on activity-based costing. Accounting, 1(2), 89-94.

Khoury, C. Y., \& Ancelevicz, J. (2000). Controvérsias acerca do sistema de custos ABC. Revista de Administração de empresas, 40(1), 56-62.

Kühl, C. A., Cogan, S., Júnior, J. B. A. C., \& Canan, I. (2006). A utilização do custeamento abc em uma organização contábil-uma simulação. Congresso Brasileiro de Custos, ABC, Belo Horizonte, MG, Brasil, 13.

Liba, A., Robles, C., \& Bacci, J. (2001). Aplicação do sistema de custeio ABC em uma organização contábil. Revista Paulista de Contabilidade, 16(480), 6-13.

Mauad, L. G. A., \& Pamplona, E. D. O. (2001). O custeio ABC em empresas de serviços: avaliação dos problemas da implantação em uma empresa de pesquisa. Congresso Brasileiro de Custos, ABC, São Leopoldo, RS, Brasil, 8.

Miranda, G. J., Carvalho, C. E. D., Martins, V. F., \& Faria, A. F. D. (2007). Custeio ABC no ambiente hospitalar: um estudo nos hospitais universitários e de ensino brasileiros. Revista Contabilidade \& Finanças, 18(44), 33-43.

Nakagawa, M. (1995). ABC: custeio baseado em atividades. São Paulo, Atlas.

Pereira, S. I. M. (2015). Custeio por atividades (ABC) e unidade de esforço de produção (UEP): similaridades, diferenças e complementaridades. (Tese de Doutorado). Universidade de São Paulo -, USP, São Paulo, SP, Brasil.

Pereira Filho, A. D., \& do Amaral, H. F. (1998). A Contabilidade de Custos como Instrumento de Informação Gerencial-Um Enfoque no Sistema de Custeio ABC. Contabilidade Vista \& Revista, 9(2), 03-14. 
Sistema de Custeio baseado em Atividades: Um estudo realizado no âmbito de uma Empresa

Prestadora de Serviços Contábeis

Célio Beserra de Sá, Antônio André Cunha Callado

Rodrigues, A. T. L., \& Lemos, I. S. (2009). Ferramentas de gestão para organizações contábeis. ConTexto, 9(16), 1-20.

Rosa, E. B. (2006). Indicadores de desempenho e sistema ABC: o uso de indicadores para uma gestão eficaz do custeio e das atividades de manutenção. (Tese de Doutorado). Universidade de São Paulo - USP, São Paulo, SP, Brasil.

Santos, E. S. (1998). ABC: Méritos, Limites, Superações. Contabilidade Vista \& Revista, 9(1), 51-58.

Stefano, N. M. (2011). Gerenciamento de custos em pequenas empresas prestadoras de serviço utilizando o Activity Based Costing (ABC). Estudios Gerenciales: Journal of Management and Economics for Iberoamerica, 27(121), 15-38.

Stratton, W. O., Desroches, D., Lawson, R. A. \& Hatch, T. (2009). Activity-Based Costing; Is it still relevant? Management Accounting Quarterly, 10(3), 31-39.

Wernke, R. (2005). Custeio baseado em atividades (ABC) aplicado aos processos de compra e venda de distribuidora de mercadorias. Revista contabilidade \& finanças, 16(38), 74-89.

Zanetti, A. C. (2003). O processo de medições de desempenho organizacional e o método de custeio baseado na atividade (ABC). Revista Brasileira de Contabilidade, (140), 48-57.

Data de Submissão: 22/03/2020

Data de Aceite: 04/08/2020 